\title{
DISTANT IN-COMPANY FOREIGN LANGUAGE LEARNING INVOLVING UNIVERSITY STUDENTS-TUTORS
}

\author{
${ }^{1}$ Alfiya Rafisovna Masalimova, ${ }^{2}$ Gulnara Djuraevna Ikramova, ${ }^{2}$ Albina Rafisovna Shaidullina, \\ ${ }^{2}$ Gulnisa Takhirovna Gubaidullina and ${ }^{2}$ Nina Dmitrievna Apraksina \\ ${ }^{1}$ Institute of Pedagogic and Psychology of Professional Education of Russian \\ Academy of Education Kazan, Isaeva Street, 12, Tatarstan, 420039, Russia \\ ${ }^{2}$ Almetyevsk State Oil Institute, Almetyevsk, Lenin Street, 2, Tatarstan, 423450, Russia
}

Received 2014-04-10; Revised 2014-04-11; Accepted 2014-04-24

\begin{abstract}
The peculiarities of distant in-company occupation-oriented foreign language learning technology for oil industry professionals under the conditions of business and education integration in the framework of corporate education and its implementing via Electron Corporate University is taken into consideration in this article. The technology proposed suggests university students as tutors and moderators involving in on-line forums for in-company foreign language learning of oil industry professionals. The purpose of this technology is its dual focus: On the one hand, it is directed on of enterprises experts' foreign language competence forming, on the other hand-on students competence improving. Such online interaction between students, teachers and specialists of the company also contributes to students' career path realization, to enterprises cultural norms accumulation, all the participants corporate culture forming. Steps and stages for its development ensuring integrity and continuity of oil industry professionals language learning are suggested and its major blocks or modules are presented and its advantages in managing, pedagogic, personal and economic aspect are revealed and presented as for company representatives so for university teachers and students.
\end{abstract}

Keywords: Distance Learning Technology, In-Company Training, Foreign Language, Integration of Education and Business, Oil Industry

\section{INTRODUCTION}

At the end of XX and at the beginning of the XXI century, countries-world leaders accelerated the pace of socio-economic development based on the benefits' using of international scientific and technological cooperation as a part of modern globalization processes that provide the world economy not only with trade, but increasingly productive integrity through the innovations' use (Nurutdinova, 2010). Analysis of the status and development of science, techniques and technologies at the facilities of a modern economy on the one hand and educational system-on the other hand, shows an increasingly important role of their interpenetrating interaction.

One of these forms that brings together education and business, is the Electronic Corporate University, including a set of guide means of information and communication technologies with software-technical, organizational and method nature (Latipova et al., 2013).

The system which is created with its help enables to carry out staff intellectual and professional development, to select gifted professionals and to do their socio-professional adaption, to provide their Corresponding Author: Alfiya Rafisovna Masalimova, Institute of Pedagogic and Psychology of Professional Education of Russian Academy of Education, Kazan, Isaeva Street, 12, Tatarstan, 420039, Russia 
cooperation with universities and research institutes in the field of competent specialists' training taking into account the current situation in company and labor market as well as to create conditions for the latest scientific developments into professional practice activity extrapolation (ECU, 2013).

\section{MATERIALS AND METHODS}

The technique and methodology of this problem are based on the meaning of that fact, that in-company training system is to be open, dynamic, projectoriented (responsive to environment changings and educational services consumers' demands), receptive to innovations, manageable and cost-effective (Masalimova, 2013).

It is well known that under ideal conditions, the modern enterprise always ought to be in systematic renovation to master innovative technologies and create competitive products, where its management staff and personnel are to renew and learn with mobility and perspective. In the end of 80-s the educational process on workers and specialists' training and retraining for JSC "Tatneft" (Joint Stock Company) new equipment's operation and maintenance was carried out only on the basis of instructions' studying for machinery and equipment using that did not provide the required quality of industrial training. So, technical specialists' incompany training in the Republic of Tatarstan at this time was based mainly on knowledge approach.

Later, in the early 90 -s the in-company training system was focused on the current needs of the market, immediate interests of employers. Consequently, technical specialists' in-company training was based on functional-activity approach, which meant that learners, activity depended on their functions at the enterprise.

The modern period of JSC "Tatneft" is connected with an effective, flexible, self-regulating technical specialists' in-company training system, which is based on reflexive and dialogic interaction of its elements ("steak-holders"), which helps them constantly to contribute the enterprises' potency, innovative activities' infrastructure, enabling it these possibilities in independent development and enterprises' strategic objectives solving.

Technical specialists' in-company training in JSC "Tatneft" as an ideology means a value-oriented body, which designed to cultivate a replication resource, enabling to prevent negative factors and create conditions, contributing the companies' development on the basis of reflexive dialogue interaction of education and business participants, whose integration provide the entire in-company training system with self-help, self-regulation and self-organization.

The modern stage in the development of JSC «Tatneft» is connected with the need in engineers, who possess occupation-oriented foreign language skills, because the company has a number of service contracts in foreign countries: Iran, Vietnam, Oman and Saudi Arabia. In this regard in 2008 «Regulation on Central Qualification Commission» to identify the joint-stock company employees foreign language mastering degree is ratified on the enterprise base. This Regulation was developed in order to: Motivate employees to improve foreign languages; stimulate employees to improve the work efficiency, effectiveness and quality, to reveal joint-stock company employees who possess high intellectual level, capable to apply practically their foreign languages stills in their professional activity; to increase the efficient use of the company's personnel potency; to increase business and creative activity; to develop professional competence, business properties, staff's skills and experience; to provide opportunities for professional growth, self-realization and career development; to attract highly qualified professionals in the company.

The identification of foreign language skill's level can be carried out as in the form of individual interviews, so in the form of separate written tasks. To identify the foreign language skill's level Qualifications Commission is organized, which has the right: To identify the foreign language skill's level of enterprises' employees; to give inference in accordance with qualification requirements and the candidates, skill's level assessment's results; to make up recommendations for enterprise's director for additional salary size's establishing, differentiating in accordance with foreign language skill's level and frequency of it's using at job and this additional salary's getting period determining; in the framework of working regulations and established duties to reject applicants, who wants to be tested on foreign language skill's mastering; to refuse in written or oral replies and giving explanations on the refusals' reasons in taking into consideration of given applications; to 
modernize and contribute the regulations confining commissions' activity; to make recommendations on the questions concerning enterprises employees' foreign language practical using; to give recommendations to the enterprises' directors concerning the problems of established salary abolition in cases of foreign language skulls' seldom using by them at job, in cases of its insufficient level for professional using and in cases of skills lack or poor work with special foreign (technical, scientific), literature which is published in foreign language (Islamov, 2013).

Electron corporate university founded on the basis of JSC «Tatneft» and representing a virtual educational environment by itself contributes the oil industry professional's in-company foreign language learning. Virtual educational environment is a mechanisms set of informational and communicational technologies with software-hardware, method, organizational and technique nature (Sarlak and Hastiani, 2008; Totterman and Wulff, 2007).

Virtual environment's positive aspects are: Increasing knowledge structure making process, members new roles in educational process as well as interactivity and visualization via informational and communicational technologies. Thus, in accordance with traditional educational process an interactive educational environment, which differs by its quality from classical one, is created (Sauer, 1988).

Virtual educational environment of JSC «Tatneft» corporate university is directed on the following tasks solving: Group training on special educational curricular and courses of study; individual tutoring on special curricular and courses; independent learning of disciplines, documents and other educational papers; videoconferences, forums and other forms of knowledge distant sharing using; students' knowledge testing and estimation.

Electronic Corporate University represents its educational resources for free availability of all who wants and needs it and limited availability for certain personnel's categories (Kozhuharova and Branenkova, 2010).

Personnel Department of the Company in collaboration with an interdisciplinary experts' group are responsible for constant searching and estimating of curricular and teaching and method materials' content in e-learning process. Departments and services in their activities' directions carry out constantly renovation of their education content, which is located on portals (Mukhametzyanova and Shaydullina, 2011).

The Election Corporate university portals has oil industry professionals' occupation oriented incompany foreign language learning multi-agent technology, the necessity of which was justified by the enterprises' social order to organize training and technique process support of JSC "Tatneft" professionals in on- line English learning.

\section{RESULTS}

The effective foreign language teaching of enterprises employees forced us to suggest the idea of student- tutors' using at its forums. It was offered in order to help the JSC «Tatneft» professionals in difficulties' overcoming in educational content and they could ask for help on-line from Almetyevsk State Oil Institute's students and, consequently, students could ask for help from these professionals working under their course and diploma projects. This approach is based on reflexive and dialogue interaction of its members and provides education and business integration, contributing to effective realization of distant foreign language learning of technical specialists. This in-company net technology of technical specialist on occupation-oriented foreign language teaching is based on business and education integration and represents a following combination of steps and phases by itself.

\subsection{Analytical and Predictive}

Oil-industry professionals' in-company training development's analysis; enterprises specialists' foreign language shills levels' analysis; the selection of students with high level of foreign language skills to act as tutors in enterprises' employees foreign language teaching; evaluation and selection of perspective professionals who has managing skills;

\subsection{Actually-Designed}

Foreign language teaching contents' selection and structuring, which includes informational, intercultural and research components of enterprises' representatives and students' professional communication, the combination of which contributes 
to their effective reflexive and dialogical net interaction in foreign language.

\subsection{Organizational and Methodical}

The implementation's development algorithm of incompany occupation-oriented foreign language learning network technology; scientific and methodical recommendations' development for enterprises' representatives, students and moderators in dealing with the technology.

\subsection{Correction and Implementation}

Discussion on the developed technology at Scientists' Councils, universities academic councils' Bureaus, as well as at companies meetings; revealing of factors and conditions, which impede the process of companies' representatives, students and moderators on-line network communication in foreign language; its correction work.

The developed distant technology of in-company occupation-oriented foreign-language learning for oilindustry professionals includes the following blocks:

- Self-presentation block in which student's personal data, his name, age, duty, business functions, social work and interests are indicated

- Educational content's block (tests, practical tasks, texts)

- Interactive block, by which is proposed in-company training members' interaction with the help of forums and chat

- Design and research works' block, involving compatible work of enterprises' representatives and students of Almetyevsk State Oil Institute on course, diploma projects, conference reports in foreign language

- Blocks of foreign and native innovative techniques and technologies in oil-extraction field, which includes their illustrated and detailed description in foreign language

- Electron library block, where the resources are located in most convenient way for their searching and using

- E-portfolio block, in which students' achievements are pointed out

Recommendations and consultations' block, devoting to mutual enrichment of both enterprises' representatives and students (professional activity experience- for students and foreign language mastering -for enterprises' representatives). Enterprises representatives' and teachers' recommendations on diploma project designing well as students' recommendations, formed by them in difficulties' overcoming process at foreign language learning are placed.

According to the results, which are presented in the Table 1, it can be stated that the process of distant inhouse foreign language teaching with the help of student-Tutors gives more effective results in terms of companies specialists foreign language competence forming. Enterprises' representatives have the right to choose individual foreign language learning trajectory: Academic or professional level. Academic level means foreign language skills' systemic applications in new professional situations; it is characterized by search and realizing of professionally valuable information in the context of professional activity. This level also means projects making in foreign language which are directed on new ideas' algorithms finding. Professional level means mastering of basic notions, professional vocabulary in foreign language, specific problems' analysis in foreign language, its decomposing into subtasks, as well as necessary knowledge skills' actualization which were learned in the frame of several topics.

Table 1. Levels of JSC "Tataneft" employees foreign language competence forming (\%)

\begin{tabular}{|c|c|c|c|c|c|c|c|c|c|c|}
\hline \multirow{2}{*}{$\begin{array}{l}\text { Levels of foreign } \\
\text { language competency } \\
\text { Years }\end{array}$} & \multicolumn{5}{|c|}{$\begin{array}{l}\text { Employees, who studied with } \\
\text { the help of students-tutors }\end{array}$} & \multicolumn{5}{|c|}{$\begin{array}{l}\text { Employees, who studied without } \\
\text { help of students-tutors }\end{array}$} \\
\hline & 2010 & 2011 & 2012 & 2013 & 2014 & 2010 & 2011 & 2012 & 2013 & 2014 \\
\hline Low & 21,4 & 17,5 & 20 & 31,6 & 18,2 & 28,1 & 34,6 & 32,2 & 18,9 & 32,5 \\
\hline Medium & 45,7 & 67,5 & 62,6 & 56,4 & 68,9 & 54,8 & 56,4 & 63,2 & 69,8 & 57,5 \\
\hline High & 32,9 & 15 & 17,4 & 12 & 12,9 & 17,1 & 9 & 4,6 & 11,3 & 10 \\
\hline
\end{tabular}




\section{CONCLUSION}

Thus, in conclusion, it should be noted that the proposed in-company training technology for occupation-oriented foreign language learning for oilindustry employees contributes to:

In organizational aspect: Carry out the corporate management of in-company training process; cooperate between oil companies of highly developed and developing countries on international level; integrate specialized educational institutes of vocational education with science and research institutes; manage the professional qualification's advancement of oilindustry enterprises' specialists in on-line regime; forecast the regional oil industry enterprises' activity due to the oil resources' reduction.

In pedagogical aspect: Transform the traditional model of foreign language teaching into an innovative multi-agent one, which is based on reflexive and dialogic interaction of the process members in foreign language learning; provide employees trajectories' professional advancement and carrier promotion; identify enterprises specialists with high level of foreign language skills who is capable to use them at their jobs doing their professional duties; form the system of eternal communications, which provide enterprises' culture models' transmitting; choose an individual trajectory of foreign language learning taking into account their capacities.

In personal aspect: Form oil-industry specialists' foreign language competency; improve their informational competency; form sincere interest in foreign language learning, which means their real communication in on-line regime; advance professional growth, carry out self-realization and promote staff's carrier trajectory; form staff's corporate culture, which makes the enterprise more attractive; to communicate with foreign colleges in foreign language.

In economical aspect: Get undergraduates, who satisfy needs of modern enterprises, to reduce time and finance expenses on their further in-company training; optimize expenses on their own specialists' training for enterprises; to complete the enterprises' deficit in labor resources via foreign language teaching without leaving by hem their working place; solve enterprises up-to-date problems, because the students become new ideas' generators; minimize offices for foreign language learning process in conditions of in-company training.

The presented online technology can be used not only at specialists foreign language in-house training, but also at specialists in-house training on different directions of their professional activities and ecoaching implementation.

\section{RECOMMENDATION}

This article does not claim to be a complete solution to the problem of oil industry specialist's foreign language on-line teaching. In further research it is necessary to develop the content blocks of the presented technologies for online learning in the aspects of professional activity and to take into consideration the conditions and mechanisms of its expansion in a number of enterprises.

\section{REFERENCES}

ECU, 2013. Electronic Corporate University. Date Views 01.01.13.

Islamov, A.E., 2013. Innovative approaches to the integration of education on the basis of information technologies. Proceedings of the Modern Lines of Theoretical and Applied Research Conference, (MLT '13), pp: 44-47.

Kozhuharova, G.M. and D.I. Branenkova, 2010. Creating educational environment for the training of mathematics teachers in the use of IT in the educational process. Discussion J., 5: 103-107.

Latipova, L.N., Z. A. Latipov and A.E. Islamov, 2013. Intensification in the content of methodic training a teacher of technological education. Middle-East $\mathbf{J}$. Scientific Res., 16: 1175-1177. DOI: 10.5829/idosi.mejsr.2013.16.09.11976

Masalimova, A.R., 2013. Corporate Training the Mentors. 1st Edn., Printing Service-XXI Century Press, pp: 183.

Mukhametzyanova, G.V. and A.R. Shaydullina, 2011. Regional Integration Processes in the Vocational Education System. 1st Edn., Idel Press, pp: 232.

Nurutdinova, A.R., 2010. Differences of eastern and western approaches: Cluster system policy and regional development in the era of globalization. J. Discuss., 7: 82-88.

Sarlak, M.A. and A.A. Hastiani, 2008. Trust in Virtual Universities. J. Soc. Sci., 4: 237-245. DOI: $10.3844 /$ jssp. 2008.237 .245

Sauer, T.S., 1988. The effects of computerized and conventional study guides on achievement in nservicett.pdf. college students. J. Comput. Based Instruct., 15: 80-82.

Totterman, A. and G. Wulff, 2007. What a social capital perspective can bring to the understanding of information sharing in a university context. Inform. Res. J., 12: 75-77. 